\title{
Design and Implementation of Physical Education Teaching System Based on Information Technology
}

\author{
ZhiWu Zhang \\ TianJin Unversity of Technology Tianjin, Tianjin 300384, China \\ Hust89@163.com
}

\begin{abstract}
Keywords: Modern education technology, Education platform of universities, Physical education, Sharing resources
\end{abstract}

\begin{abstract}
The thesis is a combination of the domestic and overseas current situation of application of modern teaching techniques in college physical education. It has made a full use of the modern teaching means which take the $360^{\circ}$ mirror teaching system as experiment to have a try of the revolution of physical education in order to optimize the physical education model and serve a reference for enhancing the quality of education.
\end{abstract}

\section{Introduction}

The reforms of physical education teaching methods are more and more emphasis on the combination of educational theory and practice, and tend one fold to the comprehensive. Innovative education is an extension, ecpand and deepens of the quality education; it is an important way of cultivating high-quality creative talents. Based on the study of physical education teaching methods with the innovative education concept, not only can promote physical education teachers to update their concepts, to change their roles, and to improve teaching quality and efficiency, but also can create a learning environment for students' independent thinking, the courage to explore, constant innovation, to help students master learning methods, to form a correct attitude and physical education values. It aims to provide a reference for promoting the theoretical research of school physical education, for enriching and innovating the modern physical education teaching [1-2].

Knowledge economical time makes the focus of international competition to be economical and scientific competition, the key point of which is the competition of human resource, especial of the high-quality human resource. High education including sports bears the burden of cultivating compound and creative human resource, while the current situation of physical education in high school is not optimistic. It needs reforming. Modern educational technology comes into being with the development of informational scientific technology and soft scientific technology. It is the result of high development of modern technology. It has changed the running and developing mode in various fields and people's way of life and study. It has greatly influenced high education including sports [3]. Thus making use of it becomes an inevitable way to deepen the reform of physical education in high school [4].

The $21^{\text {st }}$ century is a new century when human beings have a fully access to the Information Society. Multimedia technology and network technology as the core of the modern educational technology has become a creative approach to expand human capabilities. With the development and wide application of the modern educational technology [5], education is going to take on the modernization features and the trends of development. Involved in the trends of physical education in college and physical education in information technology, modern educational technology used in sports teaching has become the most important topic. Modern physical education in college is the direction of our country's development of higher education [6]. The application of the modern educational to high education teaching will have a profound and positive effect on the physical education. This paper carry on an theoretical and practical investigation in physical education teaching methods with the innovative education concept, based on the formation of the teaching, movement skill, new curriculum, with the methods of literature, expert interview, questionnaire investigation, experiment [7]. 
In recent years, with the rapid development of colleges throughout the country, the application of modern educational technology has become the commanding height and breakthrough in deepening the teaching reform. In the assessment of the level of higher education system, all levels of education authorities give the bigger concern to the school's information technology and the level of the application of modern educational technology [8-9]. How to apply the modern educational technology to the University teaching reasonably has become a noticeable problem.PE teaching, as an important part of University teaching, need to make good use of the modern educational technology aiming at promoting the reform of physical education teaching.

\section{Problems on Current Physical Education from Modern Education View}

Relying on the actuality of physical education in ten colleges of one province in China, this study adopted various ways, such as Education Literature, Questionnaire, Expert Interviewing, Mathematical statistics and logical analysis, about five kinds of scientific approaches.Thinking of the teachers and students plus the management of modern education technology as the object for study, this study explores the way of application of modern educational technology to college physical teaching in the province under the direction of the modern educational thoughts and method .During the process of survey, we found that there is quiet great progress on the aspect of college's modern education in this province.

Also the build of information and application of modern educational technology have a wide development in other courses, making great achievements. However, compared to the former years when the technology has made great progress and went through a gradual process from naught to being, simple and roughness to reasonable and normalization, the application of modern educational technology still exists many serious problems and faces developing bottleneck. Firstly, it lacks a good atmosphere for smooth implementation of modern educational technology in physical education teaching; the leadership in college has a poor understanding of the modern educational technology thought; Capital investment is not enough, the students and PE teacher lack the knowledge of modern educational technology. Secondly, the lack of a good atmosphere for the smooth implementation of modern educational technology in physical education teaching, the lacks of essential equipment, the shortages of software development and the low level of the utilization of online and web-based teaching resources.

Despite of this, E-Learning is an effective mean to overcome the shortage mentioned above. First, Students' learning attitude has changed from passive to active under E-learning Environment, while teachers are only the instruction organizer, the collaborators who the students study. Students can use E-learning resources to accomplish research learning, inquiring learning, discovery learning and independent learning and with the information tools to solve practical problems. They also can choose proper learning environment according to their interests likes and dislikes, in which way to improve their participation and enthusiasm for study.

Second, Students' study process is full of strategic, creative and cooperative. Under the environment of E-Learning, learners with high learning motivation can engage in learning process and be responsible for their study. They can work cooperatively with others to achieve targets and objectives. Most of them have enough learning enthusiasm and clear learning goals to solve problems and accomplish missions. Besides, they can finish their knowledge construction in true-life and rise to the challenges. Thus to promote the teaching form from passively accepted to actively received. Compared with traditional classroom teaching, the ability of students can be broadened greatly.

The last but not the least, Students can interact with computer simulation environment to achieve experimental learning. There is virtual library, virtual teaching community, and simulation laboratory and so on. To these learners, E-learning mode has changed their cognitive process. The proper appliance of all kinds of media such as text, images, pictures, audio files, videos, has made the learning contents visualized, which can lead the students to the law of development directly. Besides learners can communication with teachers and classmates or others via synchronous or no-synchronous interaction and virtual simulation. By these means, learners can improve their ability 
of knowledge acquiring and information processing. They can improve their spirit of team-work and innovation as well.

\section{Modern Teaching Method and E-learning Application in College Physics Education}

Constructivism Learning Theory regards the study as the course of the construction knowledge by students initiatively, and the learning situation must be similar to a real one. It provides a powerful theory support for E-learning in modern time. In light with this theory, college physics teachers in our university dedicate to create digital physics learning platform (such as multimedia computer and network) and physics digital resources (including digital physical virtual experiments, multimedia demo software, physics videos and audio files, physics websites, E-mails, BBS, distance education etc.) to create reasonable teaching situation and academic environment. Students here can study independently or cooperatively. The management platform of higher physical education resources is shown in Fig.1.
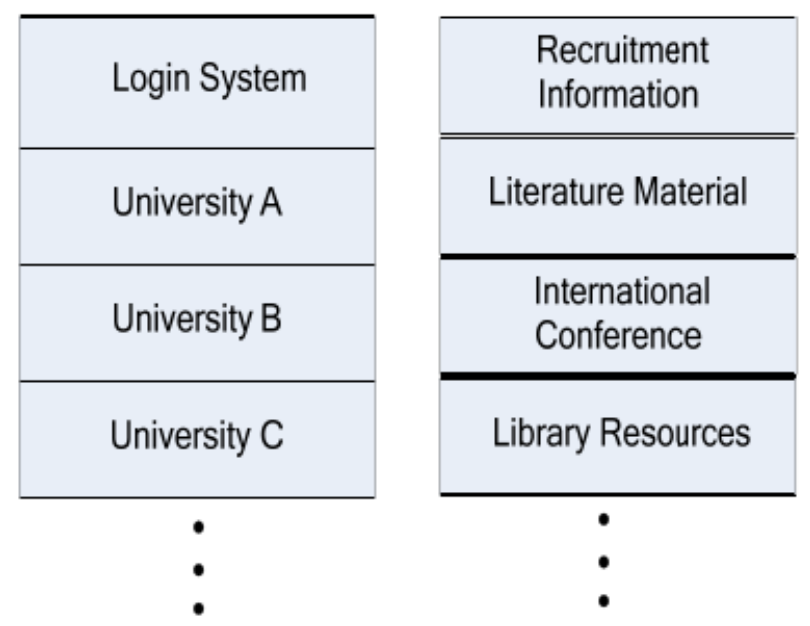

Fig. 1 Management platform of physical education resources

In classroom, teachers lead students to creative study with multiple-media, to help students with understanding the laws of physics much faster, more deeply and more comprehensively. During the teaching, teachers can properly use all kinds of instructional media such as blackboard-writing, electronic lesson plans, multimedia courseware (Flash demo courseware's and OpenGL 3D demo courseware), and demonstrative experiments to help student with physics study. Students can preview and review, or know teaching objectives and teaching program and the schedule via information sharing with E-learning (via Internet).With the application of Mobile learning system, they can use mobile phones to answering on real time during the class.

There is Online-learning and offline-learning in after-school learning mode. Online-learning after school means students' learning via Internet at their will; we have developed online reading system, online discussion system, online test and study monitoring and online course for students. Besides, teachers can mark the homework online, share their idea via BLOG. Offline-learning is realized by interesting physics competitions, physics inquiry experiments, physics creative practice and so on. We have accomplished several funny activities, this improved students' interest greatly.

Since neither classroom learning nor after-school study can achieve the greatest teaching effect. The best way is to combine the two modes. That is Blending learning. The meaning of Blend-learning is to mix the advantage of E-learning with traditional classroom learning, thus to gain the greatest teaching effect. In essence it is a way to guide and improve transitional teaching. So it is very suitable for college physics teaching. About virtual learning environment, special physics study websites we developed include technological university physics teaching system and network course. These platforms take more attention to the action between teachers and students during online-learning, works show of students, cooperative inquiry function and so on. Beyond those, we pay attention to the cross between online action and offline action. We take more aspects in to consideration before design, like arrangement of teaching contents; choice of the evaluating; recommendation of content 
after-class and practice of the teachers' heuristic education. Students can find requests of physics learning, and know the clear analysis of the difficult and doubtful points. Students can download or watch the teaching resources from the websites, and self-management on the platforms.

There is 3D digital physics teaching platform where after login, students can watch virtual experiments demonstration, and do virtual experiments online; especially for those dangerous operating experiments, students can do analog simulation on this platform. Using web2.0 technology, the digital physics teaching platform developed provides a basal 3D man-machine interactive programmable platform for students and teachers to independently develop physics courseware, and develops demo courseware suitable for teachers to demonstrate at classes and software suitable for students to study independently and interactively. We build the platform to enhance students' learning interest of physics; to improve students' ability of observing, analyzing and solving physics problems; and facilitate communications and discussions between physics workers.

\section{Conclusions}

It has been found that E-learning is an effective way to improve physics teaching. It can both facilitate students' ability of DIY and independent innovation. Under E-learning environment, students have many ways to learn; they can rethink their Knowledge Architecture in time; they can get the chance to communication with specialist and share with other learners.

Although E-Learning has brought abundant learning resources and Convenient and interactive collaborative learning to us, it will not instead of teachers in teaching. It can realize some goals in education but will never replace traditional classroom teaching and school teaching. There are new problems that to be solved, for instance, E-learning depends on Internet, once the network breaks down, these resources will become disabled. The best way for our teachers and students is to insist blend-learning. Beside we do should help the students with discrimination of the information in the E-Age.

\section{References}

[1] Mladen A. Vouk. Journal of computing and information technology CIT 1G. 2008.4: 235-24G.

[2] Won Kim. Cloud Computing: Status and Prognosis’ Object Technology, vol. 8, no. 1, 2009, 2: 65-72.

[3] Wang Chunxiang, Zhu Jun, Meng Lingkui. Modeling of the Interactive Virtual Classroom Based on VRML. Geospatial Information, 2009.

[4] SONG Qiang, ZHAO Hong- bo. Simple Discussion on the Application of E-Learning in Universities, 2009.

[5] Yao,Hongjiao. Design and Development of Teaching Platform for Remote Experiments. Shanghai: Tongji University (in Chinese), 2011.

[6] Wang Yanfeng, Duan Fengfeng. Study of personalized teaching system based on web2.0. Proceedings of the 2008 International Symposium on Computational Intelligence and Design, v1, p 524-528, ISCID, 2008.

[7] Lu,Yanji, Hu,Dejing\&Chen,Mingnan. Physical Experiment Courses. Shanghai: Tongji University Press (in Chinese), 2009.

[8] HOU Quan-jun. Base on Flash Desk of Multimedia Long-distance Teaching System. Hunan Univeristy, 2008.

[9] GONG Yue-qin. Research on the Development of Multimedia Courseware Based on Software Engineering, Huadong University, 2004. 